\title{
PSYCHE
}

Vol. 73

March, 1966

No. I

\section{THE HABITS OF PHEIDOLE RIDICULA WHEELER WITH REMARKS ON HABIT PATTERNS IN \\ THE GENUS PHEIDOLE (HYMENOPTERA: FORMICIDAE)}

\section{By William S. Creighton ${ }^{1}$ Department of Biology, City College, New York}

During 1965 the writer was able to study seven colonies of $P h$. ridicula at $\mathrm{La}$ Feria, Texas. The observations in this paper were made on these colonies or on individuals transferred from them to observation nests. There are few North American ants as poorly known as $P h$. ridicula. When W. M. Wheeler described this species in 1916 he had seen three specimens, all majors (I). One of these (the type) was taken by C. L. Scott at Brownsville, Texas. The other two, in the collection of the U. S. National Museum, came from San Diego, Texas, a town about 140 miles northwest of Brownsville. Except for these locality records no field data for ridicula were available and, as far as can be determined, no additional records have been published for this species.

The nests of ridicula are surprisingly difficult to find and this seems to be the reason why the species, which is a door-yard ant in the lower Rio Grande Valley, has escaped observation for the past fifty years. To judge from the La Feria colonies, ridicula prefers to nest in areas where there is a heavy cover of weeds, often nettles, common sunflower, Johnson grass and careless weed. These weeds not only conceal the nests but also the foragers which come from them. During December 1964 I made repeated visits to an area where there were two flourishing colonies of ridicula. It is now apparent that I often stood directly above these nests but neither was discovered until the covering weeds were removed. There are other features which make the nests of ridicula hard to find. A mature colony of this ant contains at least seventy-five majors and three

${ }^{1}$ Professor Emeritus, City College, New York

Manuscript received by the editor February 11, 1966

Published with a Grant-in-Aid of Research from the Society of the Sigma $X i$. 
hundred minors. These figures are based on totals secured by prolonged baiting of two of the colonies. Since neither nest was put out of action by the baiting it seems certain that the estimate is on the conservative side, yet there would be justification for the view that a much smaller population was present. There is rarely a conspicuous accumulation of excavated soil or of chaff around the nest entrance, for both are brought to the surface gradually and in small quantities. Even when a crater is built its diameter seldom exceeds three or four centimeters. Moreover, the crater is a transient structure for, since ridicula mixes the chaff with the excavated soil particles, the texture of the crater is loose and light and it is easily scattered by wind or rain. Hence much of the time the only indication of a ridicula nest is the nest entrance itself. This is never more than five millimeters in diameter and, more often, its diameter is about two millimeters. In addition, the nest entrance is frequently blocked up and drifted over with windblown dust and detritus. Early in this study the writer found it necessary to mark the nest entrances in order to be sure of their exact position.

There is a simple explanation for most of the above features. While ridicula will sometimes bring in other seeds, it is mainly interested in those of the careless weed, Amaranthus palmeri. These seeds are matured throughout the year, hence there is an ample supply of them at all times and large numbers are not garnered seasonally. Morecver, a great many of the palmeri seeds are free of any covering when they are brought to the nest. As a result there is no occasion for the production of a large chaff pile or an extensive crater since, in the genus Pheidole, both these features usually result from a seasonal excess of grass seeds which must be stripped and stored ${ }^{2}$.

The soil in which ridicula nests is the Victoria loam, a fine-textured, compact soil which is virtually stone free. As the walls of excavations made in it are slow to crumble, there was every reason to expect that a ridicula nest could be fully exposed. Actually this proved to be impossible. It was easy to trace the main nest passage, which consists of an unbranched shaft of remarkably uniform diameter (about $2 \mathrm{~mm}$.) that descends vertically through the soil to a depth of about thirty-two inches. It was not difficult to demonstrate the existence of lateral passages leading away from the main shaft, for the workers would open up the transected ends of these passages

\footnotetext{
2Similar considerations apply to $P h$. cerebrosior Wh. which mainly garners the seeds of desert portulacas (P. oleracea Linné and P. retusa Engl.). This crop is seasonal but, since the seeds are bare when brought to the nest, no chaff pile results.
} 
in the walls of the excavation. But to follow these passages to their cnds was quite another matter. Although some of them were traced to a distance of two feet from the main shaft, no brood chamber or seed chamber was found. Nevertheless, it is possible to state that the nest of ridicula is diffuse with the seed and brood chambers widely separated.

The foraging responses of ridicula are flexible and this makes them difficult to describe. Much of the foraging occurs at night but it is misleading to characterize ridicula as a nocturnal forager. If the nest area is shaded, or if the day is overcast, foraging may occur over a twenty-four hour period. Even when the nest is not shaded foraging ordinarily continues until mid-morning. Foraging may be diffuse or the foragers may form columns. Most of the seeds brought in are picked up from surface litter and in this type of foraging columns rarely form. But when a concentrated food source is at hand, the foragers will converge on it and a column may result. The foragers seldom get far from the nest. In each of the seven colonies most of the foraging was done within ten feet of the nest entrance. The majors take no part in the foraging although they will leave the nest with the minors. When they do so they restrict their patrol to the area around the nest entrance and it is exceptional to find them more than a foot from it. During vigorous foraging there may be several majors outside the nest and their activities effectively clear the area of other ants.

There is little about the appearance of the major of ridicula to suggest its lethal behavior. From a structural standpoint Wheeler's choice of name is apt enough, for it would be hard to imagine a more top-heavy ant. But there is nothing ridiculous about the major in action. When it is on guard, either within the nest entrance or outside it, it attacks other ants with such efficiency that the victim usually has no chance to defend itself. The basic features of this attack are the same as those described for the major of militicida in 1959 (2). As the ridicula major approaches its victim the mandibles are opened to their widest extent. This is followed by a rapid lunge towards the victim during which the mandibles are snapped shut. Unlike the militicida major the major of ridicula does not hold the antennae close to the head during attack. They are usually held with the scapes at right angles to the long axis of the head and with the funiculi flanking the open mandibles (See Fig. I). Because of the lateral expansion of the genae the mandibles can be opened to an astonishing extent, with the result that the major of ridicula seldom has difficulty getting the head or the thorax of its victim 


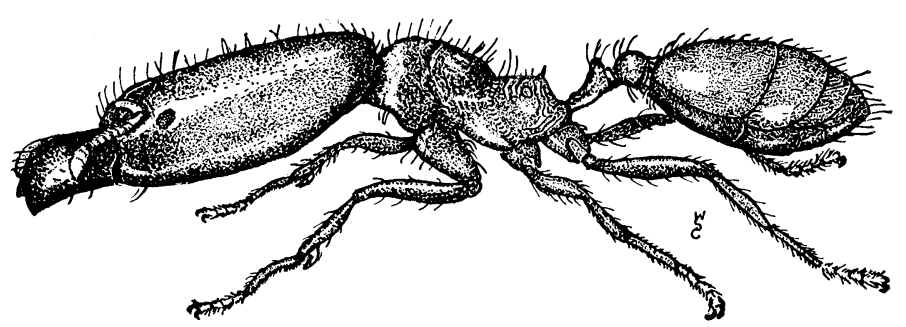

Fig. 1. Major of Pheidole ridicula in the position it assumes when about to attack another ant.

between the mandibles. Perhaps this is why the ridicula major is much less deliberate in its attack and will strike the victim anywhere. Moreover, when the major of ridicula is aroused it will sometimes charge its own minors by mistake. It seldom kills them for the minor usually dodges under the closing mandibles to a safe position below the major's head. Nevertheless minors of ridicula are sometimes crushed by their own majors. In the encounters which occurred daily around each of the nests, the majors of ridicula rarely got the worst of it. They disposed of the majors of Ph. floridana, metallescens and dentata with ease and had little trouble with those of Solenopsis geminata. They wosuld occasionally kill workers of Pogonomyrmex barbatus although this species was more often driven away than killed. There can, howcver, be no doubt about the high efficiency of the major of ridicula as a guard.

In addition to its activities as a guard the major of ridicula also functions as a seed crusher. Each of the flowers of Amaranthus palmeri produces a single, shiny, black seed about one millimeter in diameter, which resembles a tiny, blunt-edged discus. When these seeds are ripe they may fall out through a transverse slit which develops in the ovary wall or the ovary may be shed with the seed inside it. The minors strip the ovary wall away from such seeds after they are brought to the nest and the small amount of chaff which accumulates around the nest entrance is the result of this stripping. As far as could be determined the minors of ridicula cannot open the palmeri seeds; at least they never did so in the observation nests. When the major opens one of these seeds it picks it up by closing the mandibles on the lateral surfaces of the seed. Increasing pressure on these surfaces ultimately shatters the seed. In the observation nests the majors opened a number of seeds in quick 
succession. Their contenits were then gradually eaten away by the minors. The majors take little interest in the seeds after they have opened them.

The behavior of ridicula runs counter to the "classic" view of the habits of Pheidole in several important respects. This view states that most species of Pheidlole gather large quantities of grass seeds during a harvest period in late summer or early fall. These seeds are carried to the nest, stripped, and stored in seed chambers. The discarded hulls are built into a chaff pile. As a result of this the colony is provided with an abundant store of seeds which carries it over the time when no seeds are available. The account is usually rounded off with the statement that the stored seeds are opened by the major, whose large head and powerful jaws adapt it for seed crushing. There is nothing illogical in the above view. The only trouble is that, as the habits of the genus Pheidole become better known, it seems to fit fewer and fewer species.

Let us look for a moment at the matter of the use of stored seeds during periods when none are available. It is possible that a few species of Pheidole whose ranges extend into the northeastern United States (Ph. bicarincita, davisi, morrisi and pilifera) may behave in this fashion, for climatic conditions there often prohibit foraging over a period of five or six months. But this is assuredly not true of the bulk of our species, most of which forage all year long or at least for the greater part of the year. In addition, it can often be shown that there is no harvest period in the sense that the seeds are garnered when they have matured. Many species of Pheidole collect their seeds from surface litter and this litter furnishes a supply of seeds that may be worked for months after the seeds have ripened. The "harvest" may thus proceed throughout the entire winter and into the spring. Ph. macclendoni, militicida and ridicula all behave in this way. It seems plain enough that these species are not storing seeds against a period when seeds are not available, for there is either no such period or, if one exists, it is too brief to be of any significance.

There is the even more disturbing fact that many species of Pheidole do not confine themselves to a diet of seeds. No other North American species of Pheidole gathers greater quantities of seeds than does $P h$. (M.) rhea. A large nest of this species may have several bushels of chaff around the nest entrances. But, when the foraging columns of rhea are observed it may be seen that the foragers often bring in seeds and insect remains in equal numbers. Allowing for 
the far smaller size of its colonies, the same behavior is true of $P h$. creighton. The matter becomes even more complex when it is necessary to deal with species which bring in insect remains during most of the year and gather seeds only at intervals. Such species are exceptionally difficult to handle for, unless they make a conspicuous chaff pile, which they often fail to do, the only way to prove that they have gathered seeds is to expose the seed chambers in the nest. This behavior is found in Ph. bicarinata, cerebrosior, sitarches, rugulosa and xerophila. It is only by stretching a point that these five species can be considered as harvesters, since their main reliance is on insect food. This leads directly to the problem of the strictly carnivorous species of Pheidole. In the writer's opinion there are considerably more of these than has been supposed. As early as 1908 W. M. Wheeler had recognized that $P h$. dentata and hyatti are carnivorous and predacious (3). In 1955 Creighton and Gregg showed that $P h$. titanis is termitophagus (4). In 1964 the writer pointed out that $P h$. (G.) clydei is an entomophagus scavenger (5). But there are other species which can be added to this list. It should certainly include $P h$. grallipes and vallicola, both of which are insectivorous and predatory. It also appears that Ph. floridana and metallescens belong here. In 1958 Van Pelt showed that both species are attracted to a variety of baits (6). But when they are not baited or allowed access to kitchen scraps, each brings insect remains to the nest. They have nor been reported as seed collectors and the writer has been unable to find stored seeds in the nests.

The above discussion should show why it is misleading to characterize Pheidole as a genus of harvesters. There is obviously no possibility of applying such a designation to the growing number of carnivorous species, nor is the situation much better in the equally large number of species which utilize insect food at least as often as they do seeds. For the truth of the matter appears to be that species which subsist mainly on seeds are in the minority in the genus Pheidole. One further detail is pertinent in this connection. It now seems probable that the major of Pheidole functions more often as a guard than it does as a seed crusher. The writer has been able to observe the guarding function in the majors of Ph. clydei, dentata, foridana, macclendoni, metallescens, militicida and ridicula. Only in ridicula has the major also functioned as a seed crusher. It is obvious that the major of a carnivorous species can have no occasion to crush seeds and the fact that the guarding function cuts across food preferences would seem to indicate that it, rather than seed crushing, is the basic response of the major of Pheidole. 


\section{Literature Cited}

1. Wheeler, W. M., Proc. New Eng. Zool. Club, 6: 29-35 (1916).

2. Creighton, W. S. \& Creighton, M. P., Psyche, 66: 1-12 (1959).

3. Wheeler, W. M., Bull. Amer. Mus. Nat. Hist. 24: 399-485 (1908).

4. Creighton, W. S. \& Gregg, R. E. Univ. Colo. Studies, 3 : 1-46 (1955).

5. Creighton, W. S., Psyche, 71: 169-173 (1964).

6. Van Pelt, A., Amer. Mid. Natural., 59: 1-57 (1958). 

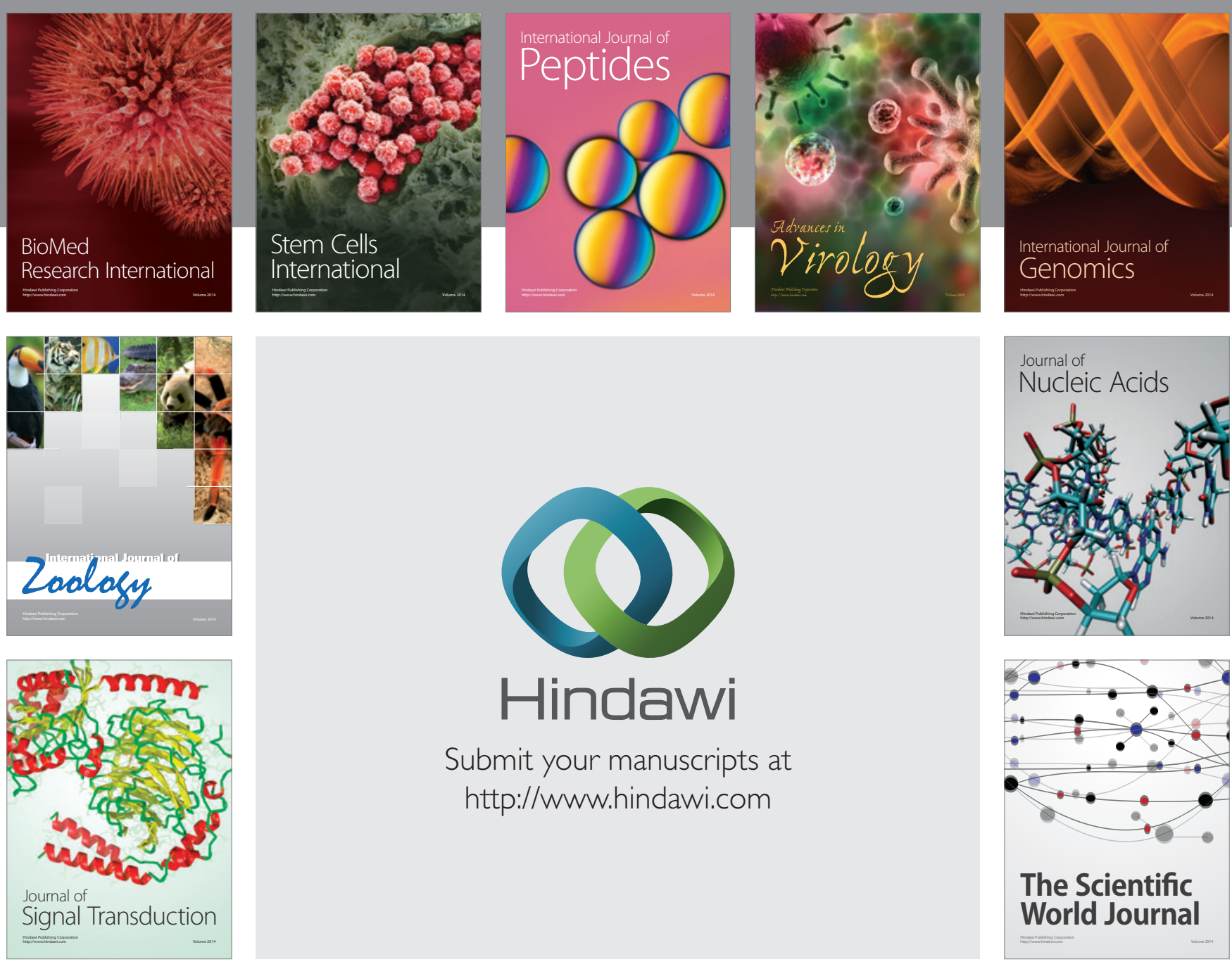

Submit your manuscripts at

http://www.hindawi.com
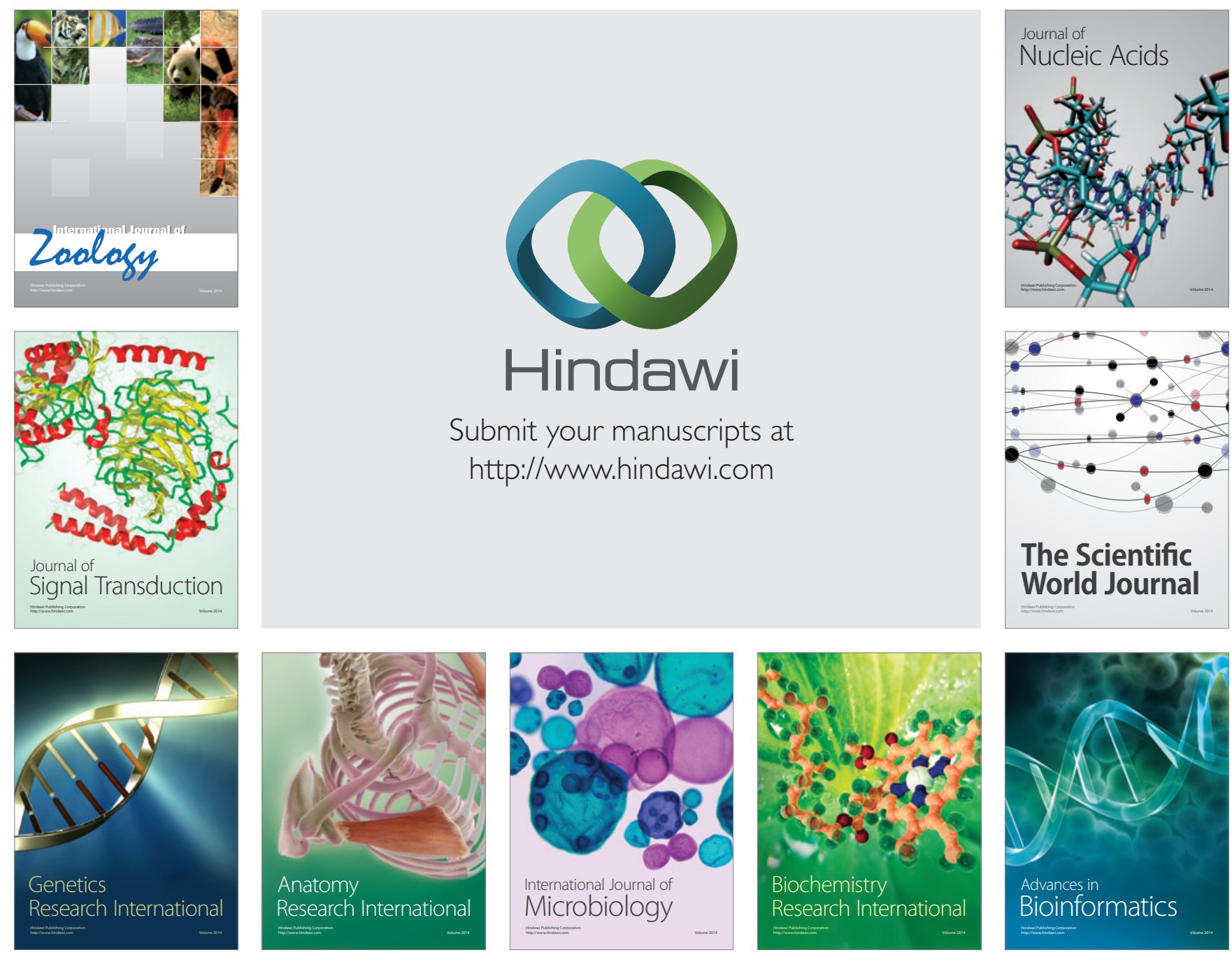

The Scientific World Journal
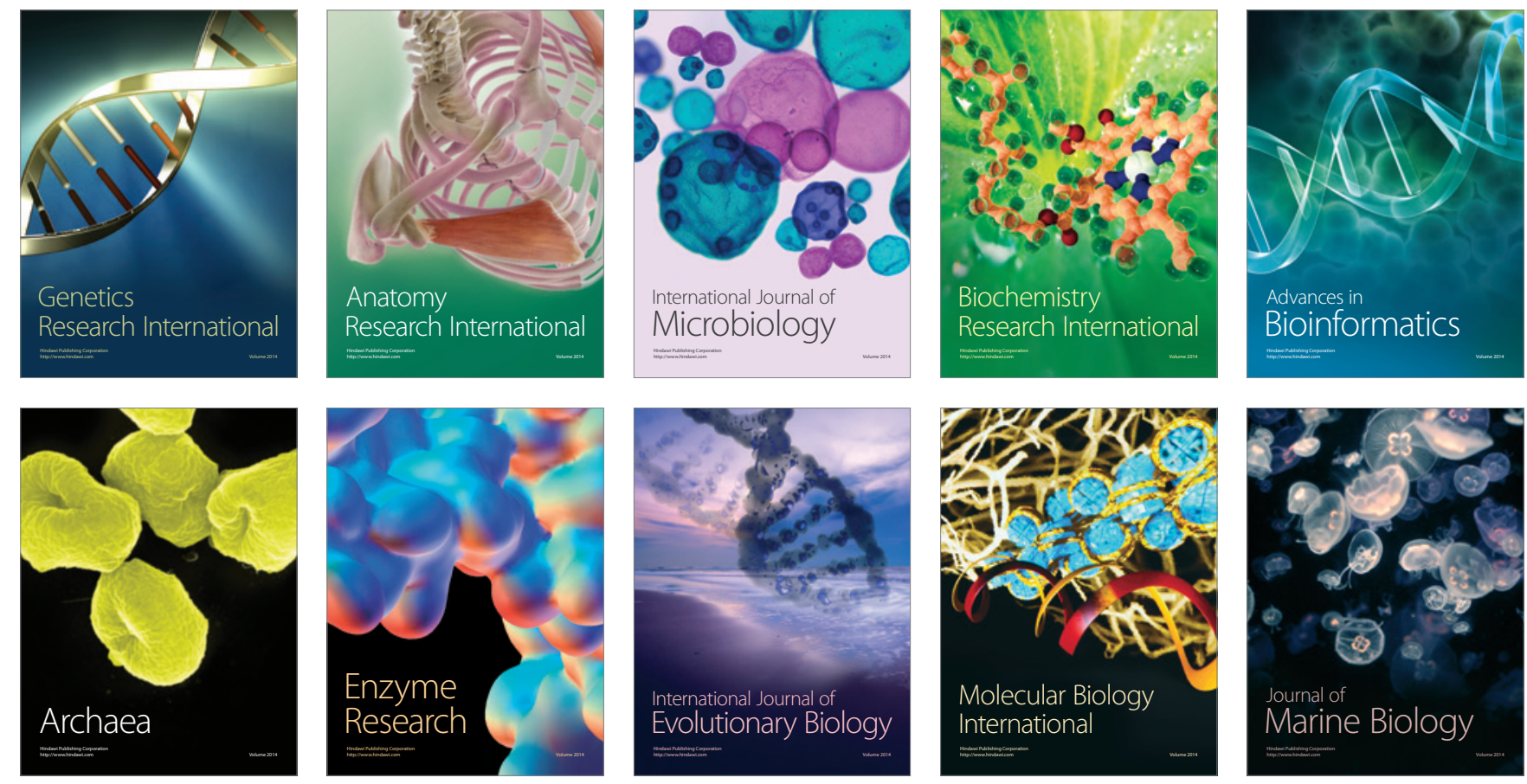